\title{
Argon plasma coagulation for successful treatment of early gastric cancer with intramucosal invasion
}

\author{
T Sagawa, T Takayama, T Oku, T Hayashi, H Ota, T Okamoto, H Muramatsu, \\ S Katsuki, Y Sato, J Kato, Y Niitsu
}

\section{See end of article for authors' affiliations \\ Correspondence to: Dr Y Niitsu, 4th Department of Internal Medicine, Sapporo Medical University School of Medicine, South-1, West-16, Chuo-ku, Sapporo, 060-8543, Japan; \\ niitsu@sapmed.ac.jp}

Accepted for publication 6 June 2002

\begin{abstract}
Background: In recent years, there has been an increasing number of cases of early gastric cancer $(T 1, N X)$ with intramucosal invasion, which are untreatable by surgical or endoscopic mucosal resection (EMR) because of their high risk. Currently, no adequate treatment is available for such patients. Aim: The main objective of this study was to evaluate whether argon plasma coagulation (APC) is an effective and safe modality for treating early gastric cancer untreatable by surgical resection or EMR. Methods: The study group comprised 20 men and seven women diagnosed with gastric cancer with intramucosal invasion who were considered poor candidates for surgical resection or EMR due to risk factors such as severe cardiac failure or thrombocytopenia. Irradiation conditions for APC treatment were determined using swine gastric mucosa. We used an argon gas flow of $2 \mathrm{l} / \mathrm{min}$ at a power setting of $60 \mathrm{~W}$ and a maximum irradiation time of $15 \mathrm{~s} / \mathrm{cm}^{2}$. The follow up period of the 27 patients ranged from 18 to 49 months (median 30 months).

Results: All lesions were irradiated easily, including areas anatomically difficult for EMR such as the gastric cardia or the posterior wall of the upper gastric body. In 26 of 27 patients $(96 \%)$ there was no evidence of recurrence during the follow up period (median 30 months). One patient showed recurrence six months after the treatment but was successfully retreated. No serious complications were found in any of the 27 patients but three patients (11\%) experienced a feeling of abdominal fullness. Interpretation: APC is a safe and effective modality for treatment of early gastric cancer with intramucosal invasion untreatable by surgical resection or EMR. However, further observations are necessary to determine the long term prognosis of patients undergoing this treatment.
\end{abstract}

A gon plasma coagulation (APC) ${ }^{1}$ is a new method for coagulating tissue which employs a high frequency electric current and ionised argon gas. APC has been used successfully for haemostasis of superficial diffuse haemorrhages from parenchyma organs, such as during laparotomy ${ }^{2}$ and laparoscopic surgery. ${ }^{3}$ In 1991, Farin and Grund $^{4}$ invented a device that can be inserted into the gastrointestinal tract endoscopically, resulting in the ability to use APC with flexible endoscopy. APC treatment is characterised by non-contact coagulation, making it possible to provide tangential irradiation to coagulate a target site uniformly. This feature is an advantage over conventional endoscopic cauterisation. Because of its ability to provide coagulation over a wide range without damaging tissues, APC treatment was first expected to find applications related mainly to blood oozing from the gastrointestinal tract or diffuse bleeding from ulcerative lesions. In recent years, Grund et al have utilised APC to reduce tumour mass, treat tumour ingrowth within a stent, and release tumour compression. ${ }^{1}$ No reports however have been published describing the use of APC as a curative treatment of gastric cancer.

The number of elderly patients with early gastric cancer ( $\mathrm{Tl}$, $\mathrm{NX}$ ) who have medical conditions that preclude either surgical resection or endoscopic mucosal resection $(E M R)^{5}$ is increasing. Local ethanol injection, ${ }^{6} \mathrm{Nd}$ :YAG laser treatment, ${ }^{7-10}$ and microwave coagulation ${ }^{11}$ have been applied in such cases. $\mathrm{Nd}$ :YAG laser treatment, in particular, is widely used in treating patients with gastric cancer as a curative or palliative therapy. ${ }^{7-10}$ However, with this method, tangential irradiation is not possible and this is an obvious drawback.

In the present investigation, to determine the appropriate irradiation settings for patients undergoing APC, we first conducted an animal experiment using swine gastric mucosa. We then treated patients with early gastric cancer with limited invasion to the mucosal layer untreatable by surgical resection or EMR.

\section{METHODS}

\section{Ex vivo experiments}

Standard APC equipment consisting of a high frequency generator (ICC 200), an automatically regulated argon source (APC 300), and a flexible APC probe $(2.3 \mathrm{~mm}$ in diameter, 100 W maximum output, and $2.4 \mathrm{l} / \mathrm{min}$ maximum flow rate) (ERBE Elektromedizin, Tuebingen, Germany) was used in this study.

Ex vivo experiments were performed to determine the irradiation conditions for APC using swine gastric walls which were obtained within one hour of sacrifice. Gastric mucosa from the two swine were examined in this study. An acrylic plate with multiple square holes $(1 \mathrm{~cm}$ each) was placed over the anterior wall of the gastric body, and irradiation was performed with the applicator (electrode) at a distance of 3-5 $\mathrm{mm}$ from the tissue. The argon gas flow rate was $2.0 \mathrm{l} / \mathrm{min}$. The power of the high frequency currents was $20 \mathrm{~W}, 40 \mathrm{~W}, 60 \mathrm{~W}, 80$ $\mathrm{W}$, and $100 \mathrm{~W}$ while irradiation times were five seconds, 10 seconds, 15 seconds, and 20 seconds. Using the formula energy $(\mathrm{J})=$ output power $(\mathrm{W}) \times$ time (seconds), the energy density $\left(\mathrm{J} / \mathrm{cm}^{2}\right)$ tested in this experiment ranged from 100 $\mathrm{J} / \mathrm{cm}^{2}$ (20 Wxfive seconds) to $2000 \mathrm{~J} / \mathrm{cm}^{2}$ ( $100 \mathrm{~W} \times 20$ seconds). The irradiated swine gastric walls were fixed in $4 \%$ formalin solution. An incision was made in the centre of each $1 \mathrm{~cm} \times 1$

Abbreviations: EMR, endoscopic mucosal resection; APC, argon plasma coagulation; EUS, endoscopic ultrasonography. 


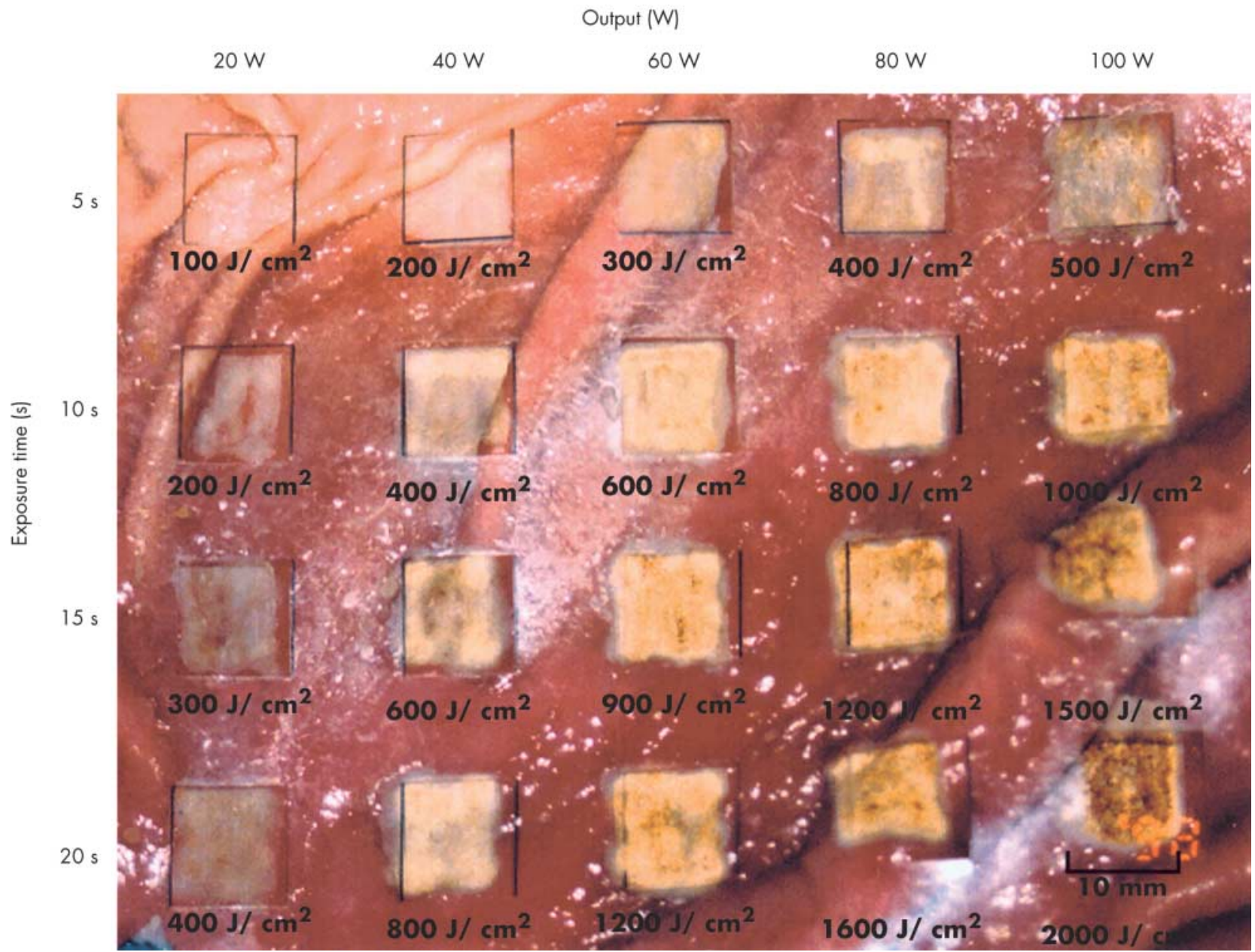

Figure 1 Macroscopic findings of swine gastric mucosa irradiated by argon plasma coagulation (APC) under various conditions. The effect of APC was macroscopically studied on swine gastric samples at $20,40,60,80$, and $100 \mathrm{~W}$, with pulse durations of $5,10,15$, and 20 seconds. The mucosa exposed to a greater output power of high frequency current and/or for a longer pulse duration underwent more conspicuous colour change from white to brown.

$\mathrm{cm}$ irradiation field, and the harvested gastric mucosal specimen was stained with haematoxylin and eosin and Elasticavan Gieson. Depth of coagulation was measured for five loci, $2 \mathrm{~mm}$ each, on the $10 \mathrm{~mm}$ incised face, and the mean of five measurements was calculated.

\section{Patients}

We enrolled 27 patients; 20 men and seven women, mean age 78 (SD 7) years, who had early gastric cancer with limited invasion to the mucosal layer. The histological diagnosis was well differentiated adenocarcinoma in all patients. We confirmed by endoscopic ultrasonography (EUS) that the tumour remained within the mucosal layer in all patients and that there were no lymph node metastases or distant metastases detectable by computed tomography or EUS. All patients were untreatable by either surgical resection or EMR because of high risk conditions such as severe cardiac failure or thrombocytopenia. Prior to APC treatment, all patients were given a full explanation of the procedure and written informed consent was obtained.

\section{Treatment}

Based on the results obtained using swine gastric mucosa, we developed irradiation parameters for APC to use for curative treatment of early gastric cancer. Prior to irradiation, the area around each cancer lesion to be cauterised was marked. Then, irradiation was performed in the manner determined by the ex vivo experiments; irradiation at $60 \mathrm{~W}$ for 15 seconds (900
$\mathrm{J} / \mathrm{cm}^{2}$ ) which caused the surface to become dry and the tissue to begin to change from white to brown. Cauterisation was usually performed once, and additional cauterisation was only done when endoscopic observation at seven days after the initial treatment suggested possible residual tumour tissue.

\section{RESULTS}

\section{Ex vivo experiments}

We first performed an ex vivo experiment on swine gastric mucosa to set the irradiation conditions of APC for use in the treatment of early gastric cancer in humans. Figure 1 shows the macroscopic appearance of swine gastric mucosa irradiated under various conditions. After exposure to a higher current output and/or a longer period of irradiation, there was a more conspicuous change from white to brown. Coagulation depths with various irradiation conditions based on histological analysis are summarised in fig 2 . The experiment was repeated twice using stomachs from two swine (exp 1 and exp 2 ). The results of the two experiments were almost the same. The coagulation front became deeper as the duration of irradiation was prolonged, reaching a plateau at 15 seconds after irradiation with each power setting. These findings indicated that the depth of tissue coagulation could be easily adjusted by altering the irradiation time and/or current. Thus the optimum APC treatment condition for clinical study was a current of $60 \mathrm{~W}$ with a maximum irradiation time of $15 \mathrm{~s} / \mathrm{cm}^{2}$, 

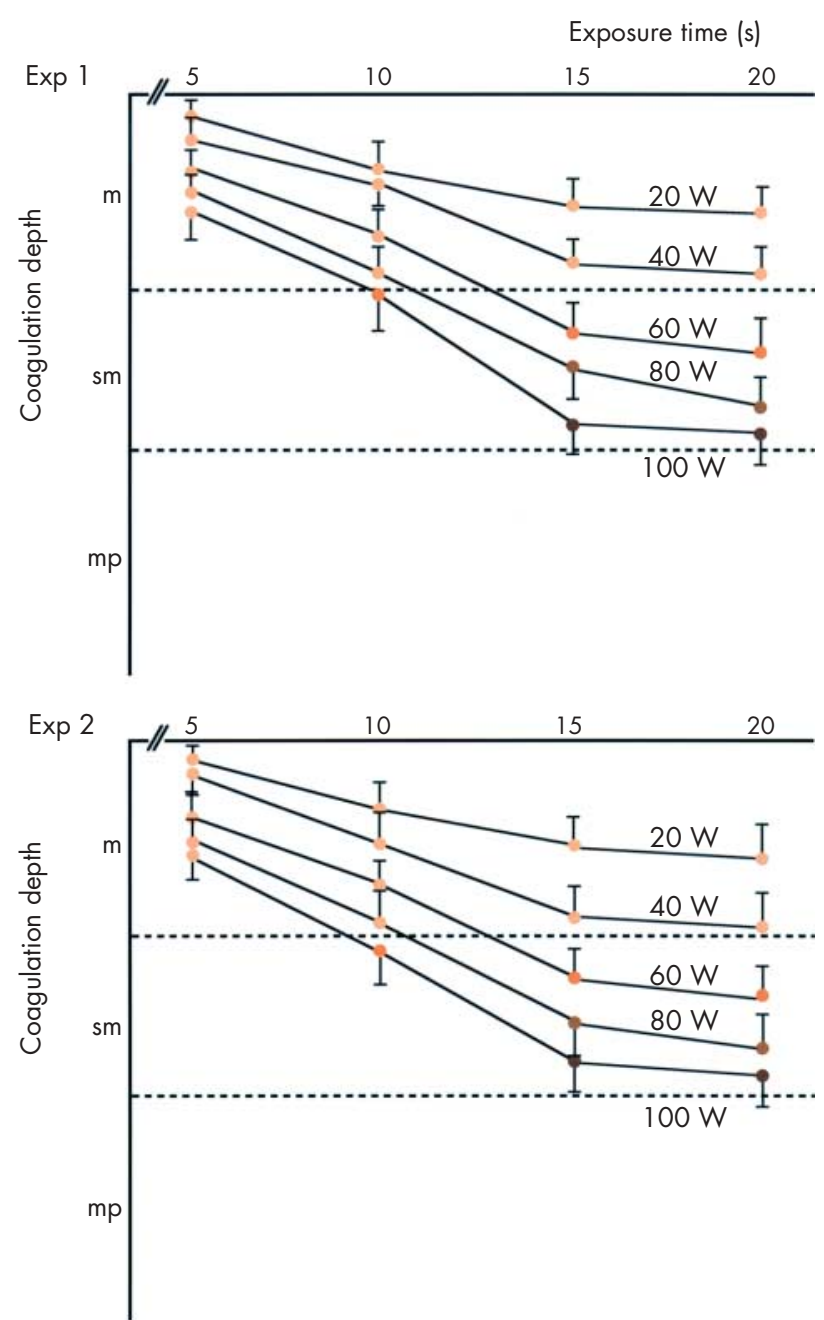

Figure 2 Coagulation depth under various irradiation conditions based on histological analysis. The experiment was repeated twice using stomachs from two swine (Exp 1 and $\operatorname{Exp} 2)$. The coagulation front became deeper as the duration of irradiation was prolonged, reaching a plateau after irradiation for 15 seconds with each power setting. It was determined that the optimum argon plasma coagulation treatment conditions for clinical study were a current of $60 \mathrm{~W}$ and a maximum irradiation time of $15 \mathrm{~s} / \mathrm{cm}^{2}$, which would not be expected to cause perforation.

which was enough to affect complete cauterisation of the tumour but not so intense as to cause tissue perforation.

Some representative histological findings of a specimen with a current of $60 \mathrm{~W}$ are shown in fig 3. Irradiation for five seconds caused necrosis of the upper mucosal layer and degenerative changes in the middle mucosal layer, and therefore the coagulation front was judged to be at the middle mucosal layer (fig 3A). After 10 seconds of irradiation, coagulation reached the deep mucosal layer (fig 3C). However, damage to submucosal collagen was not shown by Elastica-van Gieson stain, so the submucosal layer was assessed as intact (fig 3B, D). After 15 seconds of irradiation, the gastric mucosa, including the deep mucosal layer, showed obvious necrosis ( fig $3 \mathrm{E})$, and collagen showed degeneration in the upper submucosal layer (fig 3F). That is, the whole mucosal layer was coagulated by irradiation for 15 seconds with a current of $60 \mathrm{~W}$. After 20 seconds of irradiation, necrosis extended down to the superficial part of the submucosal layer (fig 3G), and there were degenerative changes in the middle part of the submucosal layer (fig $3 \mathrm{H}$ ). However, the muscle layer showed no changes after irradiation under these conditions.
Endoscopic appearance of early gastric cancers treated by APC

The gastric cancers of the 27 patients measured 14 (SD6) $\mathrm{mm}$ in diameter on average, with the largest being $35 \mathrm{~mm}$. The macroscopic types were determined in accordance with the Gross Morphologic Classification of Early Gastric Cancer at Endoscopy ${ }^{12}: 19$ patients had type IIc lesions (depressed type), five had type IIa lesions (elevated type), two had type IIa+IIc lesions (mixed type), and one had a type IIb lesion (flat type).

Effect of APC in patients with gastric cancer

Table lsummarises the results of APC treatment in 27 patients who underwent APC therapy at $60 \mathrm{~W}$ for $15 \mathrm{~s} / \mathrm{cm}^{2}$. Ten patients were not eligible for EMR as they were receiving anticoagulant therapy because of a history of severe myocardial infarction, four patients could not undergo EMR because of ulceration, and 13 patients were enrolled for APC treatment because of tumour recurrence after EMR. Twelve patients had lesions at the gastric cardia, the posterior wall of the upper gastric body, or at the lesser curvature on the antrum where adequate endoscopic access for EMR is generally difficult. Except for one patient, patients were treated only once, and the mean duration of the endoscopic procedure was 13.4 minutes. The one exception was a patient who underwent treatment three times at seven day intervals because the lesion was too large to treat at one sitting. Patients were followed up for 18-49 months (median 30 months). Recurrence occurred in only one patient $(3.7 \%)$ at six months after treatment. In this patient, the cancer had invaded the oesophago-cardiac junction, and it was difficult to cauterise completely. However, cautious retreatment with APC was successful in complete eradication of the tumour and no re-recurrence was observed for 39 months.

There were minimal complications associated with APC treatment. Three patients complained of abdominal fullness which improved soon after completion of the treatment. No patient developed perforation, bleeding, abdominal pain, or other symptoms.

\section{Representative cases}

A case of early depressed gastric cancer type llc: patient No 2 in table 1

The patient was a 70 year old man with local recurrence of gastric cancer after EMR of a lesion on the anterior wall of the antrum (fig 4A). He had been diagnosed as having progressive myelodysplastic syndrome and could not be treated surgically due to thrombocytopenia $(20000 / \mathrm{ml})$. EMR was considered unsafe due to the risk of bleeding and scarring of the lesion. Therefore, the patient was treated with APC (fig 4B). One week after treatment, an ulcer with whitish fur was noted (fig 4C). A biopsy revealed no residual tumour tissue, and the patient showed no evidence of recurrence 24 months after treatment (fig 4D)

Another case of early depressed gastric cancer type llc: patient No 12 in table 1

The patient was a 73 year old woman with an ulcerated type IIc lesion on the posterior wall of the upper gastric body. EMR was attempted but the lesion was not lifted after submucosal injection of saline because of ulceration (fig 5A, B). The patient was not a suitable candidate for surgery because of a previous myocardial infarction, and therefore APC was performed. Endoscopy at three weeks after APC treatment (fig 5C) revealed scarring of the lesion, and biopsy showed no residual tumour tissue. After 28 month, the patient showed no evidence of recurrence.

\section{DISCUSSION}

In this study, we first performed ex vivo experiments using swine gastric mucosal tissue in order to set the irradiation 

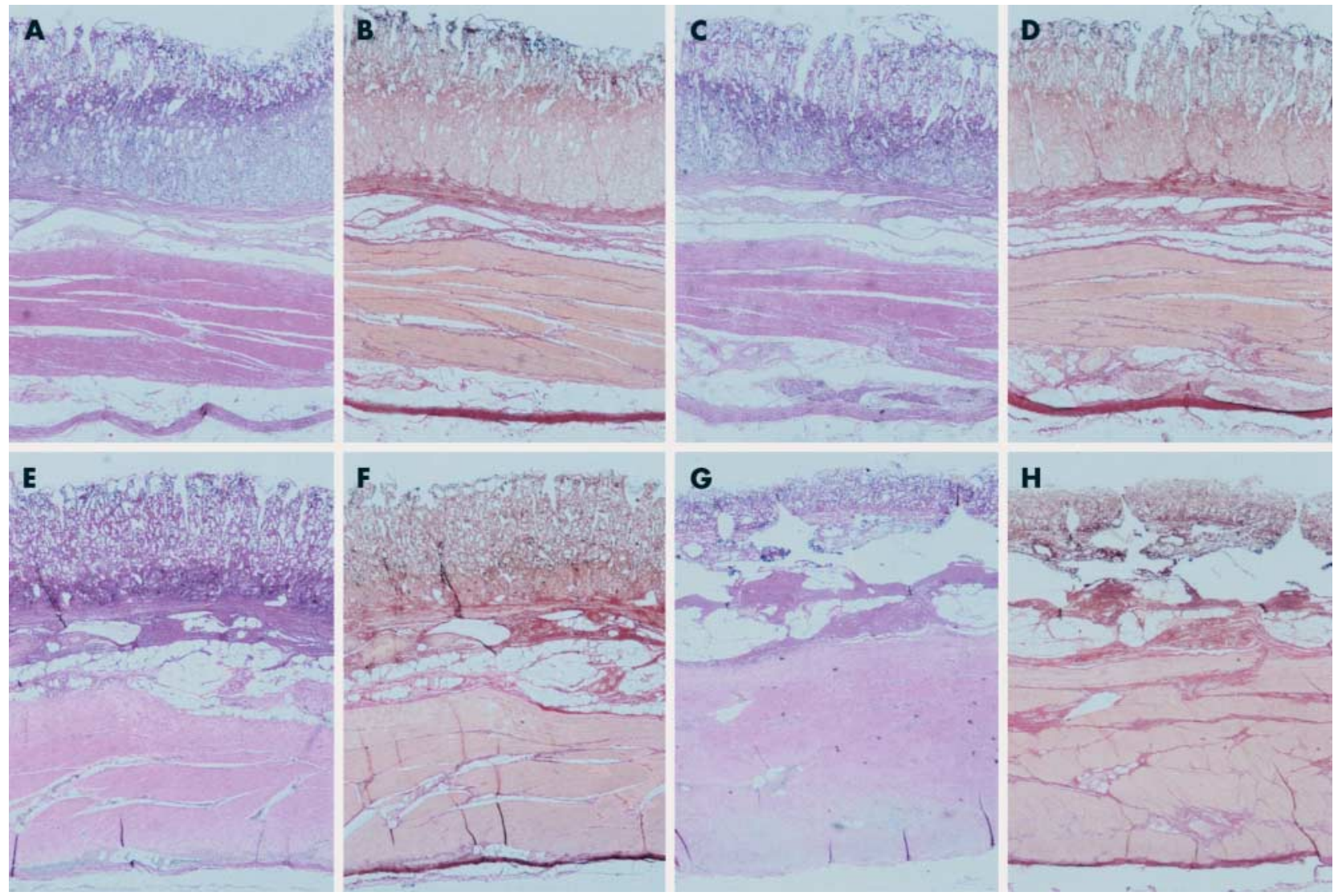

Figure 3 Histological features of swine gastric mucosa treated with argon plasma coagulation (APC) at a power setting of $60 \mathrm{~W}$ with various pulse durations. (A, B) Five seconds, $300 \mathrm{~J} / \mathrm{cm}^{2} ;(C, D) 10$ seconds, $600 \mathrm{~J} / \mathrm{cm}^{2} ;(E, F) 15$ seconds, $900 \mathrm{~J} / \mathrm{cm}^{2} ;(G, H) 20$ seconds, 1200 $\mathrm{J} / \mathrm{cm}^{2}$. Conventional haematoxylin-eosin (H\&E) stain $(A, C, E, G)$ and Elastica-Van Gieson stain $(B, D, F, H)$ were performed. Irradiation for five seconds $\left(300 \mathrm{~J} / \mathrm{cm}^{2}\right)$ caused necrosis of the upper mucosal layer and degenerative changes in the middle mucosal layer, so coagulation did in fact reach the middle mucosal layer (A). Affer 10 seconds $\left(600 \mathrm{~J} / \mathrm{cm}^{2}\right)$ of irradiation, coagulation reached the deep mucosal layer (C). No damage to submucosal collagen was identified by Elastica-Van Gieson stain after five seconds (B) or 10 seconds (D) of irradiation. The whole mucosa was coagulated after 15 seconds $\left(900 \mathrm{~J} / \mathrm{cm}^{2}\right)$ of irradiation (E). Degenerative collagen was identified in the upper submucosal layer after 20 seconds $\left(1200 \mathrm{~J} / \mathrm{cm}^{2}\right)$ of irradiation (F). Coagulation reached the middle part of the submucosal layer (G) but even at this depth the muscle layer showed no changes $(\mathrm{H})$, suggesting no risk of perforation.

conditions for APC in human. These experiments demonstrated that irradiation at $60 \mathrm{~W}$ for 15 seconds $\left(900 \mathrm{~J} / \mathrm{cm}^{2}\right)$ cauterised the whole mucosal layer but did not affect the deep submucosal layer (figs 2,3 ). Therefore, this setting should be ideal for the treatment of intramucosal cancer. Under all output settings tested from 20 to $100 \mathrm{~W}$, the depth of coagulation increased as irradiation time was prolonged and plateaued after 15 seconds. Thus the ex vivo experiment demonstrated that the depth of coagulation could easily be adjusted by changing the irradiation time and current output, suggesting that this technique is both safe and effective for human application.

However, there is a concern that the effect of APC observed in the ex vivo experiment would be somehow attenuated in vivo because in living tissue there is blood flow that may act as a heat sink, thereby decreasing the effectual temperature. ${ }^{13}$ In addition, as no in vivo study on chronological changes of coagulation depth after APC irradiation was carried out, it is difficult to assume that deeper damage would not become apparent within a few days after treatment.

With these concerns in mind, we carefully applied the APC technique for the treatment of patients with intramucosal gastric cancer who had no lymph node metastases (TINOM0) and in whom tumour eradication would be curative. As a result, APC showed a very high efficacy (no recurrence in 26/27 patients) after a follow up period of 18-49 months (median 30 months). Moreover, it should be noted that such high efficacy was obtained even with the cancers in 12 of the
27 patients located at endoscopically difficult areas to access, the cardia or posterior wall of the gastric body, probably by virtue of tangential irradiation and uniform cauterisation over a wide area.

Although preliminary, we also performed APC treatment for six early gastric cancer patients with high risk conditions who had tumours invading the submucosal layer (data not shown). In this particular trial, irradiation was performed at $80 \mathrm{~W}$ for 15 seconds $\left(1200 \mathrm{~J} / \mathrm{cm}^{2}\right)$ on the basis of the ex vivo experiments. The tumours were successfully eradicated in all patients but local recurrence was observed in one case. Therefore, this modality may be effective not only in cases of intramucosal cancer but also in cancers limited to the submucosal layer. However, a careful follow up study is needed to determine the long term prognosis of patients undergoing the treatment, particularly for the latter cases. With regard to complications, only a sense of abdominal fullness was experienced by some patients but was easily alleviated by intermittent suction or by continuous suction using a two channel endoscope. No severe complications, such as perforation, were observed, probably due to the fact that the depth of coagulation can be strictly adjusted by changing the irradiation time and power (fig 2).

APC treatment for gastric cancer has been previously reported by Wahab and colleagues. ${ }^{14}$ However, their cases were of advanced gastric cancer in whom surgery would have had neither a curative nor a palliative effect due to extensive tumour growth or metastases, and outcome of treatment was 
Table 1 Characteristics of the 27 patients with early gastric cancer enrolled for argon plasma coagulation treatment

\begin{tabular}{|c|c|c|c|c|c|c|c|c|c|}
\hline $\begin{array}{l}\text { Type of } \\
\text { cancer }\end{array}$ & $\begin{array}{l}\text { Case } \\
\text { No }\end{array}$ & $\begin{array}{l}\text { Age } \\
(y)\end{array}$ & Sex & Location* & $\begin{array}{l}\text { Diameter } \\
(\mathrm{mm})\end{array}$ & $\begin{array}{l}\text { Prior } \\
\text { treatment }\end{array}$ & $\begin{array}{l}\text { Follow up period } \\
\text { (months) }\end{array}$ & Recurrence & Complications \\
\hline \multicolumn{10}{|c|}{ Ila: elevated type } \\
\hline & 1 & 83 & $\mathrm{~F}$ & Lower body, I & 10 & $(-)$ & 30 & $(-)$ & $(-)$ \\
\hline & 2 & 83 & M & Cardia & 10 & EMR & 35 & $(-)$ & $(-)$ \\
\hline & 3 & 80 & M & Lower body, $\mathrm{p}$ & 15 & EMR & 32 & $(-)$ & $(-)$ \\
\hline & 4 & 83 & $\mathrm{~F}$ & Lower body, I & 20 & EMR & 38 & $(-)$ & $(-)$ \\
\hline & $5+$ & 77 & M & Cardia & 35 & EMR & 33 & $(-)$ & Intermittent abdomoinal distension \\
\hline \multicolumn{10}{|c|}{ Ilb: flat type } \\
\hline & 1 & 73 & M & Antrum, I & 5 & EMR & 24 & $(-)$ & $(-)$ \\
\hline \multicolumn{10}{|c|}{ Ilc: depressed type } \\
\hline & 1 & 82 & M & Antrum, I & 5 & $(-)$ & 25 & $(-)$ & $(-)$ \\
\hline & 2 & 70 & M & Antrum, a & 10 & EMR & 36 & $(-)$ & $(-)$ \\
\hline & 3 & 87 & $M$ & Antrum, I & 10 & EMR & 24 & $(-)$ & $(-)$ \\
\hline & 4 & 81 & $\mathrm{~F}$ & Lower body, $\mathrm{p}$ & 10 & $(-)$ & 21 & $(-1)$ & $(-)$ \\
\hline & 5 & 81 & $M$ & Lower body, p & 10 & $(-1)$ & 33 & $(-)$ & $(-1)$ \\
\hline & 6 & 74 & M & Upper body, p & 10 & $(-)$ & 35 & $(-)$ & $(-)$ \\
\hline & 7 & 80 & $M$ & Antrum, a & 10 & $(-1)$ & 32 & $(-1)$ & $(-1)$ \\
\hline & 8 & 83 & $\mathrm{~F}$ & Antrum, $p$ & 10 & $(-1)$ & 49 & $(-)$ & $(-1)$ \\
\hline & 9 & 84 & $M$ & Cardia & 15 & EMR & 29 & $(-)$ & $(-)$ \\
\hline & 10 & 78 & M & Lower body, p & 15 & EMR & 18 & $(-)$ & $(-1)$ \\
\hline & 11 & 81 & M & Lower body, I & 15 & $(-)$ & 36 & $(-)$ & $(-)$ \\
\hline & 12 & 73 & $\mathrm{~F}$ & Upper body, $\mathrm{p}$ & 18 & $(-)$ & 28 & $(-)$ & $(-)$ \\
\hline & 13 & 57 & M & Upper body, p & 15 & $(-)$ & 24 & $(-)$ & $(-)$ \\
\hline & 14 & 81 & M & Lower body, I & 15 & $(-)$ & 45 & $(-)$ & $(-)$ \\
\hline & 15 & 80 & M & Cardia & 15 & $(-)$ & 31 & $(-)$ & $(-)$ \\
\hline & 16 & 76 & M & Antrum, I & 15 & $(-)$ & 25 & $(-)$ & $(-)$ \\
\hline & 17 & 73 & $\mathrm{~F}$ & Lower body, $\mathrm{p}$ & 15 & $(-)$ & 20 & $(-)$ & $(-)$ \\
\hline & 18 & 73 & $M$ & Lower body, I & 20 & EMR & 30 & $(-)$ & $(-1$ \\
\hline & 19 & 70 & M & Lower body, $\mathrm{p}$ & 20 & EMR & 21 & $(-)$ & $(-)$ \\
\hline \multicolumn{10}{|c|}{ \|la+\|c: mixed type } \\
\hline & 1 & 87 & $\mathrm{~F}$ & Cardia & 15 & EMR & 45 & $(+)$ & Intermittent abdomoinal distension \\
\hline & 2 & 67 & M & Mid body, g & 20 & EMR & 33 & $(-1)$ & Intermittent abdomoinal distension \\
\hline Mean (SD & & 78 (7) & & & $14(6)$ & & $30(7)$ & & \\
\hline
\end{tabular}

*I, lesser curvature; g, grater curvature; $a$, anterior wall; $p$, posterior wall.

†Type lla: case 5, was treated three times.

EMR, endoscopic mucosal resection.
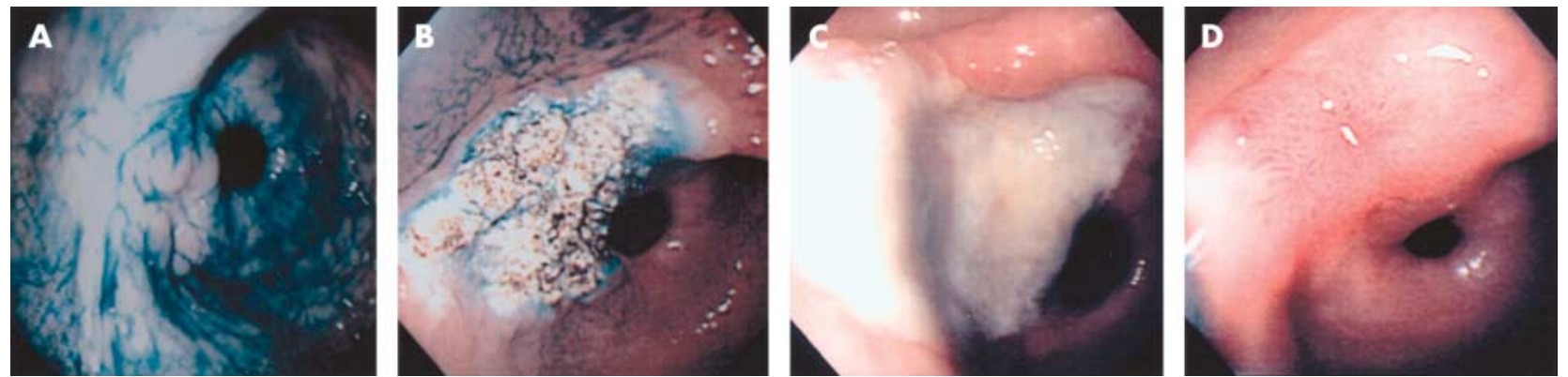

Figure 4 A case of early gastric cancer type llc (depressed type): patient No 2 in table 1. Age/sex: 70 years/male. Location: antrum, anterior. Size: $10 \mathrm{~mm}$ in diameter. Type: llc (depressed type); residual lesion of post endoscopic mucosal resection. Depth: intramucosal invasion. Pathology: well differentiated adenocarcinoma. Comorbid factors: myelodysplastic syndrome, cerebral infarction. (A) Before irradiation; (B) immediately after irradiation; (C) one week after irradiation; and (D) six months after irradiation.

palliative with shrinkage of tumour and alleviation of symptoms.

There are several other modalities for local treatment of gastric cancer. Nd:YAG laser therapy has been used widely in patients with gastric cancer that is untreatable by surgical resection or EMR. However, two of the disadvantages of the $\mathrm{Nd}$ :YAG laser are its inability to irradiate tangentially and its relative expense compared with APC treatment. ${ }^{15}{ }^{16}$

Photodynamic therapy has also been used to treat early gastric cancer. ${ }^{17-20}$ Photodynamic therapy ${ }^{21}$ is based on the uptake of a photosensitising dye by target cells, which are damaged by reactive oxygen intermediates generated after irradiation with light that has a wavelength matching the dye absorption spectrum. Although there is selective toxicity for tumour cells and a very low incidence of serious complications, ${ }^{22}$ photodynamic therapy has several disadvantages such as cutaneous photosensitivity, a long stay in the dark, and a high cost, ${ }^{23}$ which are not factors in APC treatment.

In addition, microwave coagulation was also used for the treatment of gastric cancer by Tabuse and colleagues. ${ }^{11}$ However, they treated only three patients with early gastric cancer, the majority being treated for palliative relief of advanced gastric cancer, indicating that the efficacy of microwave coagulation for early gastric cancer is still unclear.

Thus APC has advantages over previous therapies in terms of tangential irradiation and inexpensive compact equipment.

\section{CONCLUSION}

We used APC in 27 patients for the treatment of early gastric cancer that was untreatable by either surgical resection or EMR. The procedure was safe and no patient developed serious complications. In all cases, tumour tissue was 

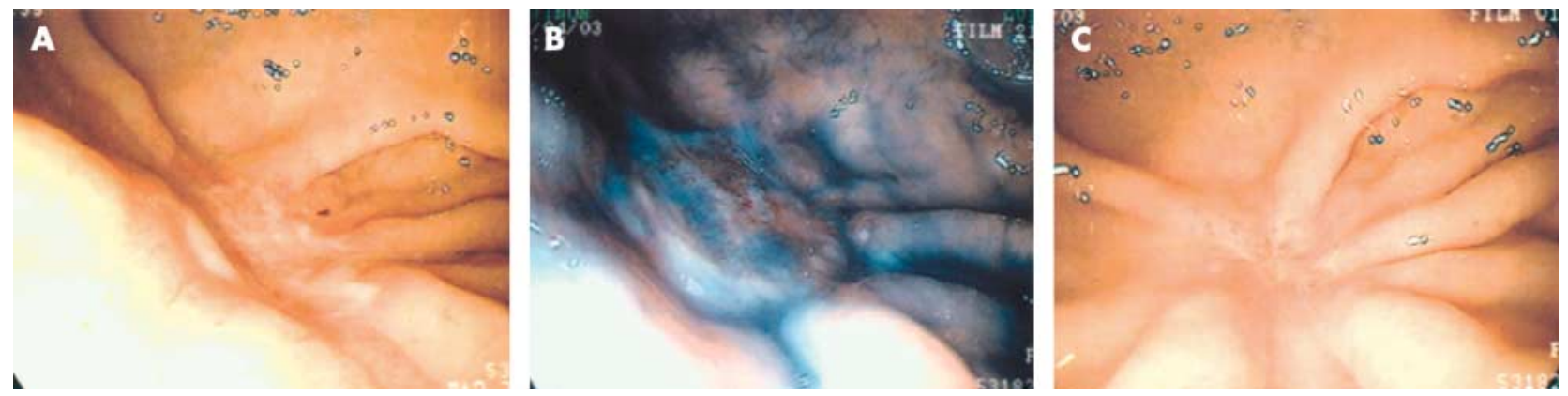

Figure 5 Another case of early gastric cancer type llc (depressed type): patient No 12 in table 1. Age/sex: 73 years/female. Location: upper body, posterior. Size: $18 \mathrm{~mm}$ in diameter. Type: llc (depressed type) with ulcer formation. Depth: intramucosal invasion. Pathology: well differentiated adenocarcinoma. Comorbid factors: myocardial infarction, cerebral infarction (A, B) Before irradiation; and (C) three weeks after irradiation.

completely eradicated and necrosis was observed, suggesting that APC may be used as a means of curative treatment for early gastric cancer without lymph node or distant metastases. However, follow up is necessary to evaluate the long term prognosis of patients undergoing this treatment.

\section{ACKNOWLEDGEMENTS}

We would like to express our deep appreciation to Dr Ikeda for his valuable advice on haematoxylin and eosin (H\&E) stain and ElasticaVan Gieson stain.

\section{Authors' affiliations}

T Sagawa, T Takayama, T Oku, T Hayashi, H Ota, T Okamoto, H Muramatsu, S Katsuki, Y Sato, J Kato, Y Niitsu, Fourth Department of Internal Medicine, Sapporo Medical University School of Medicine, Sapporo, Japan

\section{REFERENCES}

1 Grund KE, Storek D, Farin G. Endoscopic argon plasma coagulation (APC): first clinical experiences in flexible endoscopy. Endoscopy 994; $2: 42-6$

2 Brand E, Pearlman N. Electrosurgical debulking of ovarian cancer: a new technique using the argon beam coagulator. Gynecol Oncol 1990;39:115-18.

3 Daniell J, Fisher B, Alexander W. Laparoscopic evaluation of the argon beam coagulator. Initial report. J Reprod Med 1993;38:121-5.

4 Farin G, Grund KE. Technology of argon plasma coagulation with particular regard to endoscopic applications. Endosc Surg 1994;2:71-7 5 Ono H, Kondo H, Gotoda T, et al. Endoscopic mucosal resection for treatment of early gastric cancer. Gut 2001;48:225-9.

6 Imaoka W, Ida K, Katoh T, et al. Is curative endoscopic treatment of early gastric cancer possible?. Endoscopy 1987;19(suppl 1):7-1 1.

7 Yasuda K, Mizuma Y, Nakajima M, et al. Endoscopic laser treatment for early gastric cancer. Endoscopy 1993;25:451-49.
8 Hiki Y, Shimao J, Yamao Y, et al. The concepts, procedures, and problems related in endoscopic laser therapy of early gastric cancer. A retrospective study on early gastric cancer. Surg Endosc 1989;3:1-6.

9 Sibille A, Descamps C, Jonard P, et al. Endoscopic Nd:YAG treatment of superficial gastric carcinoma: experience in 18 Western inoperable patients. Gastrointest Endosc 1995:42:340-5.

10 Tajiri H, Oguro Y. Laser endoscopic treatment for upper gastrointestinal cancers. J Laparoendosc Surg 1991;1:71-8.

11 Tabuse K, Katsumi M, Nagai Y, et al. Microwave tissue coagulation applied clinically in endoscopic surgery. Endoscopy 1985;17:139-44

2 Sano T, Kobori O, Muto T. Lymph node metastasis from early gastric cancer: endoscopic resection of tumour. Br J Surg 1992;79:241-13.

13 Welch AJ, Wissler EH, Priebe LA. Significance of blood flow in calculations of temperature in laser irradiated tissue. IEEE Trans Biomed Eng 1980;27:164-6.

14 Wahab PJ, Mulder CJ, den Hartog G, et al. Argon plasma coagulation in flexible gastrointestinal endoscopy: pilot experiences. Endoscopy 1997;29:176-81.

15 Kaassis $M$, Oberti E, Burtin $P$, et al. Argon plasma coagulation for the treatment of hemorrhagic radiation proctitis. Endoscopy 2000;32:673-6.

16 Johanns W, Luis W, Janssen J, et al. Argon plasma coagulation (APC) in gastroenterology: experimental and clinical experiences. Eur J Gastroenterology: experimental and clinici

17 Nakamura T, Ejiri M, Fujisawa T, et al. Photodynamic therapy for early gastric cancer using a pulsed gold vapor laser. J Clin Laser Med Surg 1990;8:63-7.

18 Ell C, Gossner L, May A, et al. Photodynamic ablation of early cancers of the stomach by means of mTHPC and laser irradiation: preliminary clinical experience. Gut 1998;43:345-9.

19 Mimura S, Ito Y, Nagayo T, et al. Cooperative clinical trial of photodynamic therapy with photofrin II and excimer dye laser for early gastric cancer. Lasers Surg Med 1996;19:168-72.

20 Spinelli $\mathbf{P}$, Mancini A, Dal Fante M. Endoscopic treatment of gastrointestinal tumors: indications and results of laser photocoagulation and photodynamic therapy. Semin Surg Oncol 1995;11:307-18.

21 Dougherty TJ, Kaufman JE, Goldfarb A, et al. Photoradiation therapy for the treatment of malignant tumors. Cancer Res 1978;38:2628-35.

22 Bown SG. Photodynamic therapy in gastroenterology-current status and future prospects. Endoscopy 1993;25:683-5.

23 Lui $\mathbf{H}$, Anderson RR. Photodynamic therapy in dermatology: recent developments. Dermatol Clin 1993;11:1-13 